\title{
Feedback Experience of Online Learning During the COVID-19 Pandemic: Voices from Pre-service English Language Teachers
}

\author{
Min Yang ${ }^{1} \cdot{\text { Pauline } \text { Mak }^{2} \text { (I) } \cdot \text { Rui Yuan }}^{3}$
}

Accepted: 23 August 2021

(C) De La Salle University 2021, corrected publication 2022

\begin{abstract}
Informed by the notion of help seeking (Newman, 2008), this study aims to examine a group of MATESOL students' online feedback experience in relation to their professional learning during the COVID-19 pandemic. Analysis of interviews with the participants and their written reflections produced during the online courses revealed that while online feedback afforded learning opportunities such as the provision and reception of feedback in diverse groups within a safe space, it also created challenges such as limited real-time and extensive feedback. While the participants exhibited nonadaptive help seeking at times, they also adopted adaptive help seeking strategies for feedback, including having internal conversations with learning materials to generate feedback, creating a space for feedback and interaction with significant others, and staying resilient and finding alternatives for feedback. The paper concludes with practical implications on supporting pre-service teachers' online feedback experience and fostering their adaptive help seeking strategies in feedback situations as critical and self-regulated learners to contribute to their professional learning.
\end{abstract}

Pauline Mak

pwwmak@eduhk.hk

Min Yang

myang@ccu.edu.tw

Rui Yuan

ericruiyuan@um.edu.mo

1 Department of Foreign Languages and Literature, National Chung Cheng University, Chiayi, Taiwan

2 Department of English Language Education, The Education University of Hong Kong, Hong Kong, Hong Kong SAR

3 Faculty of Education, University of Macau, Macau, Macau SAR
Keywords Online feedback experience .

Feedback seeking · Adaptive help seeking - Strategies . Self-regulated learners

\section{Introduction}

Influenced by the COVID-19 pandemic, the form and medium of second language (L2) education has undergone unprecedented change from traditional face-to-face classrooms to online spaces. Both teachers and students need to adapt themselves to this new practice, including the provision and reception of feedback. Feedback, defined as "information provided by an agent (e.g., teacher, peer, book, parent, self, experience) regarding aspects of one's performance or understanding" (Hattie \& Timperley, 2007, p. 81), not only reveals students' learning progress and achievement but helps manage, monitor, and improve their learning. The shift of feedback online, breaking the boundaries of time and space, affords a broader capacity for interaction and social learning between the teacher and students, as well as the opportunity for increased provision of and response to feedback. Although students have more freedom and autonomy to act upon feedback at their own pace, they need to take greater responsibilities to manage the feedback or seek extra feedback to enhance their learning. This may pose difficulties for those in Asian contexts such as Hong Kong where independent and critical analytic skills and a self-regulated learning style are not often practiced (Campbell \& $\mathrm{Li}, 2007$ ). To date, there is a paucity of studies that examined how and the extent to which students solicited feedback in an online environment. Against this backdrop, this study aims to examine how a group of MATESOL students experience online 
feedback and manage it to optimize their professional learning as future English teachers. Two questions are addressed:

1. How do MATESOL students perceive and experience the online feedback mode and practice?

2. To what extent and how do they actively seek feedback to facilitate their professional learning in the program?

\section{Literature Review}

\section{Feedback and L2 Teachers' Professional Development}

This study views feedback as a process through which learners actively use comments and information from different sources to inform and improve their own learning (Carless \& Boud, 2018). Learners play a central role, where they are empowered to engage in interactions with others to obtain and negotiate feedback to facilitate learning. As such, they may actively seek feedback to confirm what they have learned; they may also use feedback to revise or restructure their understanding (Butler \& Winne, 1995). Through giving peers feedback, they could become more critical and reflective of their own work (Yu, 2019). This view concurs with Yuan and Lee's (2014) dialogic approach, which defines feedback as "all dialogue" in formal and informal situations that aids learning. Such dialogue involves joint meaning construction between the learner and those who participate in their learning process.

As pre-service teachers engage in different activities (e.g., teaching practicum, coursework, research, overseas immersion) to promote their own professional development (Farrell, 2012; Sato \& Mutoh, 2019), feedback from significant others during these activities plays an important role (Weber et al., 2018). This is because learning to teach is essentially a socio-cultural process mediated by a variety of artefacts (e.g., curriculum documents and textbooks) and stakeholders (e.g., teacher educators and peers) who can provide feedback to help mediate student teachers' cognitions and actions in specific educational settings (Johnson, 2009). As illustrated in current L2 teacher development literature, they can actively analyze their peers' feedback on their microteaching and use it to reflect upon and improve their own English teaching practice (Yuan, et al., 2020). They can also generate feedback on their own teaching practice through ongoing self-reflection in the form of reflective writing (Farrell, 2012). Such internal dialogue and self-generated feedback can inform their classroom practice, such as gaining knowledge about how to create effective English-speaking environment and increasing students' English learning motivation. The critical role of feedback on pre-service English teachers' professional learning therefore merits more research attention.

\section{Feedback Practice in Online Environment and Pre- service English Teachers' Help Seeking}

Online learning affords many benefits, such as increasing flexibility and enhancing connectedness and interactions among teachers and students regardless of time and location (Hwang et al., 2021). Sharing similar benefits, online feedback practice that can be utilized by students at their own pace can be provided in different forms, such as e-feedback on written assignment (e.g., track changes in Microsoft Word), short notes in email, oral feedback in online meetings, screen-captured video feedback, or automated feedback provided by computer (Cheng \& Li, 2020; Liu et al., 2021; Ware \&Warschauer, 2006). Also, in an online environment where students are anonymized and do not show their faces, they are more likely to share opinions with their peers and receive critical and constructive feedback (Alharbi \& Al-Hoorie, 2020; Liu et al., 2021). Moreover, in online spaces, L2 students' writing can be recorded as transcript to be commented on by themselves and their teachers for learning purposes (Yuan, 2003).

Online feedback practice is not without challenges. For instance, technical problems such as abrupt halt of online platforms can discourage L2 students' engagement with feedback (Alharbi \& Al-Hoorie, 2020). They may find it overwhelming to handle voluminous discussion threads and feedback online (Ware \& Warschauer, 2006). They might also be unaccustomed to certain forms of online feedback (e.g., videoed feedback) (Cheng \& Li, 2020). Moreover, while students may expect to receive timely and frequent online feedback on their performance or work (Mory, 2004), such feedback may not always be available. For pre-service English teachers engaged in online learning, these challenges indicate that they may need to be able to seek help to regulate their own online feedback experience and enhance their professional learning.

Help seeking includes two types: adaptive and nonadaptive help seeking (Newman, 2008). Adaptive help seeking is an important self-regulated learning strategy (Karabenick, 2006; Newman, 2002; Pintrich, 2004) referring to one's capacity to actively seek help that facilitates learning and fosters independent problem solving ability (Nelson-LeGall, 1981; Newman, 2002, 2008). As such, students focus on identifying problems encountered in learning, the kind of help needed for problem solutions, and the available sources of help (Fletcher, 2017). After critical analysis and reflection, they enlist support from various sources to address the problem. While the different 
sources of help often refer to teachers, peers, family or friends (Hsu, 2005), it may also include students themselves, since self-regulated and strategic learners can assess and monitor their learning process for self-improvement (Pintrich, 2004; Zimmerman, 2005). Adaptive help seekers are therefore goal-oriented and possess a sense of selfefficacy that enables them to deal with difficult academic learning situations (Newman, 2008).

In contrast, nonadaptive help seeking occurs when learners ask for help when it is not necessary or avoid asking for help when it is necessary (Newman, 2002, 2008). Nonadaptive help seekers may therefore appear disengaged, such as being passive or refusing to engage in resolving the challenges encountered in learning. Various factors influence students' help seeking in their learning and feedback process. Cognitively, their help seeking actions are influenced by their awareness of whether help is needed or how to elicit the exact kind of required help (Karabenick, 2006; Newman, 2002). Regarding affective-motivational factors, students' perceived competence, or cognitive and social self-perception, influence their willingness to seek help (Newman, 2008; Ryan \& Pintrich, 1997). Asking others for help can be a threat to one's self-esteem and self-worth as it may indicate inadequacy (Karabenick, 2006; Karabenick \& Knapp, 1991). For example, seeking feedback from others may exhibit a sense of embarrassment due to public evaluation of their work (Hattie \& Timperley, 2007; Karabenick, 2006). Help seeking is thus sensitive and needs to be performed skillfully. As Ryan and Pintrich (1997) found, students possessing better social skills might experience less stress when seeking help and were more willing to request help. Socially, students' help seeking is influenced by whether they know who to seek help from and how to request help appropriately (Newman, 2002, 2008).

In language teacher education literature, although the notion of help seeking has not received much attention, it can be observed in studies on pre-service English teachers' professional learning. In times of problems encountered during the teaching practicum, these teachers can actively ask their peers as sources of knowledge for feedback and suggestion. Another help seeking strategy is to actively engage in group discussion to clarify their peers' feedback on their own microteaching and asking follow-up questions for improving their future teaching practice (Yuan et al., 2020). Another source of help would be generated by the students themselves, who could reflect upon and assess their teaching practice to produce feedback for their own improvement (Weber et al., 2018). For instance, using the information gathered from multiple sources, students generate internal feedback to help them move forward in their learning (Nicol, 2020).
On the whole, the notion of help seeking explains how and to what extent pre-service English teachers search for internal and external feedback when confronted with the problems identified in professional learning. Adopting the notion of help seeking, this study examines how and the extent to which a group of MATESOL students seek feedback during online learning to facilitate their professional development.

\section{The Study}

\section{Research Participants and Context}

This study is part of a larger research project on pre-service English teachers' professional learning in university-based teacher education programs in Hong Kong. Five pre-service English teachers (i.e., Alice, Belle, Cara, Derek, Evan), who were near the end of the one-year full-time MATESOL program, joined this study voluntarily. They were Chinese and their native language was either Mandarin or Cantonese. They received a bachelor's degree in English from universities in Mainland China, except Belle, who majored in Economics in a university in the United States. All of them had some previous English teaching experience and enrolled in the MATESOL program for furthering their professional learning (refer to Table 1 for the profile of the participants). During the course of the program, they needed to take core courses in English Language Teaching methodology and second language research and electives ranging from English pronunciation to social and psychological aspects of language learning. To complete the program, they could also choose to write a dissertation in conjunction with taking coursework. As the usual practice of the program, most learning tasks were conducted face-to-face. However, because of the COVID19 outbreak, the university shifted to asynchronous and synchronous learning in the second semester. For example, in the TESOL Teacher's Professional Development course (taken by all the participants except Cara), pre-recorded teaching videos and worksheets were given to the students to work on individually at their own pace. The students were also required to write four reflections on their specific teaching problems related to the topics discussed in the lessons on an online forum and were encouraged to respond to their peers' reflections. In courses such as English Language Teaching in Practice (taken by Derek and Evan), Discourse Studies (taken by Alice, Belle and Evan), and World Englishes (taken by Cara), the course instructors and students met weekly online through Zoom, where lecturing was the dominant medium of learning. Throughout the semester, in the absence of face-to-face encounter that would normally warrant natural interactions 
Table 1 Profile of participants

\begin{tabular}{lllll}
\hline Name (Pseudonym) & Age & Native language & Years of teaching experience & Education background \\
\hline Alice & Early 20s & Mandarin & Around 3 years & BA in English \\
Belle & Early 20s & Cantonese & Around 1 year & BA in Economics \\
Cara & Early 20s & Mandarin & Around 1 year & BA in English \\
Derek & Mid 20s & Mandarin & Around 4 years & BA in English \\
Evan & Early 30s & Mandarin & Around 12 years & BA in English \\
\hline
\end{tabular}

and opportunities for feedback, students needed to seek feedback online to manage their own learning. The student data would therefore enrich our understanding of pre-service English teachers' online feedback experience and help seeking strategies.

To comply with the ethical clearance of the university, written informed consent for participation was obtained from the participants and ethical approval for the project was gained from the university prior to the start of the study.

\section{Data Collection and Analysis}

In-depth, individual semi-structured student interviews, which lasted for 60 to $90 \mathrm{~min}$ each, were conducted in English at the end of their studies. The interview focused on the participants' views about their online learning and feedback experience, including the learning opportunities, challenges, and coping strategies. Each interview was transcribed verbatim for analysis. To further understand the nature of the participants' feedback seeking, the documents produced including the participants' online written reflections, responses from their peers, and their responses to their peers' reflections in the TESOL Teacher's Professional Development course were collected.

An inductive and recursive approach was adopted to examine the interview transcript and written reflections (Charmaz, 2014; Strauss \& Corbin, 1998). At the initial coding stage, a range of codes emerged regarding the participants' positive and negative online feedback experience and their feedback seeking behavior. For instance, regarding online feedback experience, Cara and Derek offered positive views about the opportunities afforded by the online setting (i.e., enhanced willingness in administering feedback to their peers) whereas Evan and Cara gave negative views about the challenges brought by online learning (i.e., lack of interaction and feedback). Among all the identified opportunities and challenges, the more frequently mentioned ones were reported in the findings (see Table 2). In respect to the feedback seeking behavior, codes about adaptive help seeking strategies (e.g., selfgeneration of feedback) and nonadaptive help seeking (e.g., forgoing opportunities to seek assistance) were identified.
Through cross-case comparison (Merriam, 1998), the codes were further refined, giving rise to the three main themes presented in the findings. To ensure trustworthiness of the data, the authors engaged in discussion of the analysis and interpretation of the data.

\section{Findings}

\section{Pre-service Teachers' Perception and Experience of Learning Opportunities in Online Feedback Practice}

The interviews with the participants revealed that they decided to enroll in the MATESOL program in a bid to increase the expertise in English teaching to improve and benefit their work. To achieve this goal, they took different courses during their year of studies. As they experienced both face-to-face and online learning, they critically compared their feedback experience in these two learning modes. Particularly, they identified several advantages of online feedback which were otherwise not affordable in a traditional classroom setting.

For example, the breakout rooms (i.e., small group mode) on Zoom assigned by the course instructors allowed different combinations of student grouping and interactions with a wider variety of classmates in idea exchange as well as feedback provision and reception, which was not possible in a face-to-face setting. Cara shared:

Last year I couldn't talk with too many classmates because I often sat with my friends at a fixed spot. In online lessons, I can talk with different classmates every time and hear what they think about my opinions. (Cara, Interview).

Also, they felt "protected" (Cara, Interview) behind their computers and became more willing to provide comments on their peers' thoughts. Derek explained:

Some students were too shy to speak in face-to-face discussions, but they were very active online and interact with others a lot. This helped us get more feedback from each other (Derek, Interview). 
Table 2 Learning opportunities and challenges in online feedback practice

\begin{tabular}{ll}
\hline Opportunities & Challenges \\
\hline $\begin{array}{l}\text { Increased opportunities for interactions with different peers in } \\
\text { synchronous online discussion }\end{array}$ & $\begin{array}{c}\text { Limited opportunities for real-time and extensive feedback in asynchronous } \\
\text { lessons }\end{array}$ \\
$\begin{array}{l}\text { Enhanced willingness in administering feedback to peers in a } \\
\text { safe online space }\end{array}$ & $\begin{array}{c}\text { Lack of face-to-face learning, limited interaction, and little room for } \\
\text { immediate feedback in synchronous lessons }\end{array}$ \\
$\begin{array}{l}\text { Collaboration with peers and reception of feedback via } \\
\text { asynchronous communication }\end{array}$ & \\
\hline
\end{tabular}

Since they could not meet their peers regularly (i.e., as in face-to-face classrooms), some participants used online communication tools or platforms for interaction and feedback on their learning. For instance, Belle and her groupmate worked collaboratively on Google Docs to complete a group lesson plan. She appreciated the interaction and collaboration afforded by the virtual learning environment where she could receive descriptive and evaluative feedback from the peers during the process of writing collaboratively:

We typed everything we could think of about the lesson on Google Docs. When I didn't know how to handle a part of the lesson, I put my questions there. Then she gave some comments (Belle, Interview).

The virtual online platform thus promotes communication and feedback practices between students and facilitates learning.

\section{Pre-service Teachers' Perception and Experience of Challenges in online Feedback Practice}

Despite the learning opportunities brought by online feedback, the participants preferred learning in a traditional face-to-face setting because they could obtain or seek immediate feedback on their ideas from the course instructors and peers. Some online courses were conducted in the form of pre-recorded video lectures and the participants were encouraged to email questions or comments to the course instructors. The participants generally appreciated the flexible learning mode but felt that their opportunities for real-time and extensive feedback were constrained. Alice explained:

The course instructor responded quickly to my questions about the final essay in email, but I still preferred talking with him in person. Unlike speaking, we kept the language short and clear in email. That limited the kind of feedback I could get (Alice, Interview).
In Evan's experience, in the live courses on Zoom, most course participants did not show their faces and only a few actively responded to the course instructors' questions. This lack of face-to-face interaction resulted in an inactive and demotivating atmosphere for participation and interaction. After a while, some course instructors started adopting a more teacher-centered lecturing mode, where teaching was restricted to knowledge transmission. Not only did the students find learning in this way monotonous, they also believed that there was less room for interaction and feedback. Two participants reflected as follows:

It's difficult to concentrate on the online lectures especially after listening to the teacher talking for one or two hours without any interactions (Cara, Interview).

In the online courses, the teachers talked most of the time. We just listened. There wasn't much interaction with the teacher or feedback on my thought. It's a bit disappointing (Evan, Interview).

Despite the challenges, the participants understood that moving their professional learning and feedback practice online was a must during difficult times. They were able to critically think about the situation from different perspectives and empathize with their course instructors' and peers' struggles:

If I were the course instructor, I wouldn't know how to interact with so many students in an online classroom. I believe if there were only, say, six students, the course instructor would interact a lot with us and give comments to each of us (Evan, Interview).

In light of these difficulties, some participants were motivated to devise adaptive help seeking strategies to achieve their professional learning goals (i.e., to enhance expertise in English teaching). In certain situations, however, they were disengaged from the feedback process (i.e., nonadaptive help seeking), as explicated below. 


\section{Feedback Seeking Strategies}

\section{Having Internal Conversations and Feedback Interaction with the Course Materials and the Course Instructors}

To compensate for their perceived limited feedback and interactions with the course instructors, some participants decided to preview the course materials and generated questions, including points that they did not understand and thoughts stimulated by the reading. Therefore, in the online courses, they could have a conversation with the course instructor and materials in their mind and generate answers, as feedback, to their own questions no matter whether they could immediately interact with others. The self-initiated internal conversations yielded important feedback on their learning and represented their adaptive help seeking strategy to achieve professional learning goals, such as improving English teaching practice. As Evan revealed, he felt empowered by his self-initiated internal conversations and feedback:

When I watched the video lectures, I can pause anytime to understand the course instructor's meaning and respond to his questions in my mind. I have the authority to reflect upon my teaching at my own pace (Evan, Interview).

Another feedback seeking strategy, after previewing the course materials and generating questions, was to search for information online (i.e., in the library database). As the participants recalled, they would search for difficult concepts online (Evan, Interview). This not only helped them digest the course content but also enabled them to ask critical questions in the online lessons and get useful feedback. Alice reflected as follows:

I would google the new concepts to understand them beforehand. When I was in the online lessons, I could contribute my ideas more and receive feedback from others. This improved my understanding of issues in English teaching (Alice, Interview).

The participants' internal conversations and feedback interactions with the course materials and the course instructors were not always smooth, however. When the difficulty level of the learning materials was beyond their command, some just decided not to seek feedback, which suggested their orientation towards nonadaptive help seeking:

There were times when I needed help but I seldom asked others for help. If I can't understand the concepts at all, I didn't know how to put forward a question. And the opportunities for feedback were online, not face-to-face. This may make things even worse (Cara, Interview).

\section{Creating Spaces for Feedback and Interaction with Course Instructors and Peers}

Unlike in physical setting of a traditional classroom where the participants could easily talk with each other and receive feedback on their thoughts, in online courses they could not always get immediate feedback on their performance. In this undesirable situation, some just stayed passive and accepted the status quo. For instance, some participants found it difficult to make full use of the feedback designed for a face-to-face learning context in an online learning situation and chose to avoid opportunities to seek assistance. This kind of non-adaptive seeking behavior was also present in Belle, who could not act upon her course instructor's feedback on her oral presentation (i.e., about her action research) in a Zoom lesson and ignored the opportunities to seek the necessary help, such as asking the course instructors' further feedback on how to optimize her learning:

For now, I cannot administer the questionnaire to a greater number of university students or young adults like the course instructor suggested. We are all stuck at home. I cannot go to the campus to find participants (Belle, Interview).

Similarly, Cara and her peers' pre-recorded group oral presentation about issues related to English accents received no feedback from the course instructor or the peers, although they were eager for feedback for improvement. Initially, she decided not to seek feedback further, like in Belle's case. However, Cara soon realized that this nonadaptive help seeking for feedback was not helpful for her learning. That is, she needed to deliberately create a space for feedback and interaction by herself when taking online courses, especially when this kind of space was minimally "given" (e.g., in pre-recorded video lectures). Therefore, as Cara explained, later on, she decided to use email as a space to obtain feedback from her course instructor, showing her adaptive help seeking:

I sent the course instructor two outlines of my final essay. She told me one was more workable than the other. That helped me decide what to write and I got an okay grade (Cara, Interview).

Another space for feedback created by the participants was via online communication tools such as WhatsApp or WeChat. In Evan's case, he initiated discussions with two peers on WhatsApp based on the course PPT (focusing on different teaching issues). As they had taught English to 
different levels of students, they could contribute different perspectives in the discussion. This self-initiated experience exchange served as feedback for him to critically analyze and update his English teaching practice:

After we talked, we know more about each other's English teaching experience. This became a point of reference for me to analyze and improve my own experience (Evan, Interview).

Having a positive learning experience in their self-created feedback space, some (i.e., Evan, Belle) decided to sustain this form of adaptive help seeking:

Our conversation continued after we graduated. We shared our thoughts and questions about English teaching on WeChat (Belle, Interview).

\section{Staying Resilient and Finding Alternatives to Obtain Feedback}

Since online learning and feedback was a new experience to most participants, they were trying to find the most comfortable and confident ways to seek feedback throughout the online courses. They particularly needed time to get used to speaking up in Zoom lessons. When they spoke, their account name would show on the screen of all course participants' electronic devices and their voice would be the focus of attention. This differed greatly from their previous experience of speaking up in the multichanneled (e.g., oral, aural, visual) and busy setting of a traditional classroom (e.g., the course participants may not always focus on the speaker). As Alice recalled, despite the course instructors' encouragement, she still felt "shy" and "embarrassed" to speak up in the Zoom lessons (Alice, Interview). Yet she did not hope to let the psychological barrier limit the opportunities to get feedback on her learning, which urged her to stay resilient and find alternatives for feedback. An approach she used was to type her thoughts and questions in the chat box for the course instructors to respond during the Zoom lessons. This feedback seeking approach, as adaptive help seeking, effectively helped her retain learning motivation:

When the course instructor saw my message, he acknowledged it by saying "Oh, your answer was great!" and provided more responses. I was so motivated to contribute more ideas (Alice, Interview).

Not all online feedback situations were facilitative for the participants' professional learning. For example, in the TESOL Teacher's Professional Development course that most research participants took (except for Cara), students were required to write and post their reflections about issues in English teachers' professional development on an online forum (i.e., Moodle). They were also encouraged to respond to their peers' reflections and help generate solutions to the issues being raised. However, some participants were not motivated to engage in it. Belle explained:

To be honest we didn't respond a lot to our peers' reflections. We just needed to post four to six responses. Also we were not required to respond to their response in our reflections (Belle, Interview).

Because there was no specific requirement on the feedback content, some participants found that most of the peers' feedback on their reflection consisted of praises and uncritical comments containing phrases such as "thanks for sharing" or "I like your reflection" (Peers' responses to Belle's and Evan's online written reflections).

As Derek shared, this experience ran counter to his expectations in that he was eager to receive the peers' critical feedback on his written reflection about his teaching experience:

Very few comments [on the online forum] were analytical or constructive. Maybe they wanted to save my face (Derek, Interview).

In other instances, the participants received no peer feedback on their teaching problems in the reflection, such as the one presented below:

I sometimes got parents' message at midnight blaming me that their kids didn't get good test scores. Am I an English teacher or a service worker? I felt lost. Some parents don't really respect private tutors like us. It really upset me (Alice, written reflection).

In such situations, while most participants decided to just leave the issues or questions unanswered and seek no further feedback which evidenced their orientation towards nonadaptive help seeking, Derek was an exception. He remained resilient to find an alternative to obtain his desired kind of feedback. Specifically, his adaptive help strategy was to actively comment on his peers' reflections by analyzing their teaching stories and providing suggestions, hoping to stimulate meaningful discussions. For example, under a classmate's written reflection on English teacher's use of humor in class on the online forum, Derek proposed a different thought:

At the end of your reflection, you mentioned that some teachers played jokes on the students who made mistakes, and hoped that this kind of 'humor' could prevent them from making the same mistakes. But I think this is no longer a kind of 'humor' as it destroys 
students' self-esteem (Derek's response to a peer's online written reflection).

As he explained, he intended to "model critical feedback practice" for his peers and bring changes to their feedback style (Derek, Interview). He also viewed his peers' teaching experience as a reference point for examining his teaching and generating feedback to benefit his future practice:

I tried to raise a different perspective or ask a question under my peers' reflections. I also took it as an opportunity for me to experience different school contexts. I can also compare their experience with mine to help myself improve (Derek, Interview).

Overall, in the face of the challenges in online feedback practice, while some participants might decide to stay passive and seek no further help, showing nonadaptive help seeking, others remained active in initiating and generating feedback for their own professional learning, which evidenced their adaptive help seeking as critical and selfregulated learners (Newman, 2002, 2008). After experiencing the benefits of online feedback, some participants believed that they would create opportunities for their future students to engage in feedback online (e.g., using online discussion forum). As Evan shared, online learning and feedback is "the future trend" (Evan, Interview) in the ever-changing world.

\section{Discussion}

This study set out to explore how a group of MATESOL students experienced online feedback and sought feedback to facilitate their professional learning. The findings show that the participants had divided perception about their online feedback experience and exhibited differentiated help seeking behavior. While some of them felt more protected to give critical feedback on the peers' thoughts, others might feel pressured to speak up in a livestream lesson where they would be put under the spotlight on everyone's screen. The differing attitudes could be attributed to the fact that the transition from face-to-face to online mode of instruction was a novel experience to the participants which would require additional time to get accustomed to. Under this new learning mode, the participants were found to have contrasting feedback help seeking behavioral tendencies owing to different factors as explicated below.

From the cognitive perspective, the findings reveal that those who adopted adaptive help seeking for feedback evaluated and reflected upon their learning conditions and process against their goal of enhancing their professional development as English teachers, and then actively devised strategies to seek feedback from different sources and through different media to achieve the goal. This suggests that the cognitive factor of whether one is aware that help is needed or could analyze the learning problems and seek appropriate help (Fletcher, 2017; Karabenick, 2006; Newman, 2002) is goal driven. Interestingly, the participants that exhibited nonadaptive feedback seeking behavior showed awareness and admitted that they experienced difficulties that they could not overcome but adopted a laissez-faire attitude and did not exercise determination to remedy the obstacles. This might be attributed to their selfperceived limitations and incompetence of their capability as in the case of Cara who could not tolerate learning material beyond her ability and Belle who was not able to act on the feedback from the instructor.

In respect to this affective-motivational aspect, the participants' adaptiveness for feedback seeking rests upon their self-perceived readiness to receive feedback in certain forms in the online environment. As such, the findings disclosed that the participants needed to feel emotionally safe and protected to publicly share their teaching experience and get feedback in online lessons. That is, they purposefully avoided putting themselves and their performance under public examination for self-protection and self-preservation (Hattie \& Timperley, 2007; Karabenick, 2006; Karabenick \& Knapp, 1991). The ability to manage affect in undesirable feedback situations also has an important role to play. As the findings suggested, resilient pre-service English teachers can turn disappointment at negative feedback experience into a drive to search for alternatives to obtain useful feedback. For instance, Derek could think outside the box and take the initiative to model giving critical feedback to his peers, hoping to change the peers' feedback style which might eventually benefit his professional learning.

From the social perspective where help seeking is considered as a social transaction (Newman, 2008), the participants' willingness to approach the instructor for help is contingent upon their roles and relationships with others in their situated context (Karabenick, 2006). Faced with a new mode of learning through virtual classes, those participants oriented towards nonadaptive feedback seeking might hold the belief about the course instructors' lack of concern or support. On the other hand, those who seek help adaptively regulated their learning by seeking feedback from the course instructors through different means, such as Alice's use of the chat function in Zoom to initiate feedback. The participants also considered peers as an important feedback source. Through different media (e.g., WeChat, Google Docs), some tried to create a supportive learning community with their peers, which was a safe house to return to when encountering problems. Moreover, 
they could be their own feedback provider by assessing their own learning and generating feedback to monitor their learning, which concurs with the crucial attribute of a selfregulated learner (Pintrich, 2004).

The findings added a new dimension, the physical factor, to the literature on adaptive help seeking. While online learning is believed to break the boundary of time and space which increases connectedness among those who participate in it (Hwang et al., 2021), it is unlike the traditional classroom setting where participants can see each other and easily start conversations that allow feedback to naturally occur. Without adequate support or design of an effective online feedback environment, as the findings showed, the pre-service English teachers felt isolated from each other and deprived of opportunities for real-time and extensive feedback.

Another important finding was that those who adopted adaptive help seeking for feedback were able to exercise their self-regulated approach to learning and even employed a repertoire of adaptive help seeking strategies to enhance their feedback experience. This study then contributes to the feedback literature by identifying three adaptive help seeking strategies to enhance L2 pre-service teachers' online feedback experience. Firstly, through engaging in internal dialogues with the learning materials, generating questions, and actively finding answers via different sources (e.g., online courses, websites), the participants can use themselves as the instrument to obtain useful feedback on their learning. Secondly, the purposeful construction of a space via online platforms or communication tools (e.g., email) allowed the participants to quickly receive feedback from different sources and revisit the feedback at their own convenience. Thirdly, it is important to maintain a resilient mindset and find alternatives to obtain feedback that met their needs and expectations, especially when they were dissatisfied about the existing online feedback practice. These strategies evidenced their critical thinking and autonomy in feedback seeking and their effort to monitor their professional learning as selfregulated learners (Zimmerman, 2005).

Overall, the participants' help seeking, particularly regarding online feedback, is a complicated process and their motivation to seek help in feedback situations is influenced by their consideration of the cost and gains (Hattie \& Timperley, 2007) from cognitive, affective-motivational, social and physical perspectives.

\section{Implications and Conclusion}

This study contributes to enriching the current understanding of pre-service English teachers' online feedback experience and adaptive help seeking in online feedback situations. It is important to note that the study was based on interviews with as well as written reflection (i.e., collected in one online course) from the participants. Future studies might include more data sources such as pre-service teachers' recorded online interaction and feedback to obtain a fuller picture of their feedback seeking during online learning. Such data source would also reveal the feedback content to shed light on how they seek help to gain expertise as English teachers. Additionally, a longitudinal research that tracks these pre-service teachers' online feedback experience throughout an extended timeframe would disclose how their help seeking strategies develop to facilitate their professional learning.

The findings provide implications on supporting preservice English teachers' online feedback experience to benefit their professional learning. First, since these teachers are important sources of feedback for themselves and their peers, their online feedback literacy, critical thinking, and reflective ability need to be enhanced. A common opinion from the participants, as the finding showed, was the shallow comments from some of the peers, which revealed their inadequate knowledge and skills to provide critical feedback. The situation can be worse when they have little experience in providing feedback online, which differs in nature from face-to-face feedback and interaction. Therefore, teacher educators should raise pre-service teachers' awareness about effective online feedback practice and provide them with useful strategies to manage and give feedback online. For example, the three feedback seeking strategies identified in this study can be introduced to and used by these teachers to experiment and polish their online feedback strategies. To equip these teachers with the ability to provide constructive and critical feedback in online learning situations, teacher educators may involve them in exemplar analysis to raise their awareness about the characteristics of quality work, thereby enabling them to differentiate works of various levels of quality and to delineate what a piece of good work entails (Carless \& Boud, 2018). Also, when implementing learning tasks (e.g., reflection writing on forum, oral presentation via Zoom), teacher educators need to provide clear guidelines to encourage feedback and interaction among these teachers. Since online feedback is new to many teacher educators and pre-service English teachers, they need sufficient technical support from their department and university. Workshops and instructions about different features of online platforms or communication tools, especially those regarding feedback, can be provided to alleviate them from struggling with technology, which would help them adapt to online feedback practice more smoothly. 
Acknowledgements This article is based on a research project supported by a grant from the Research Grants Council of the Hong Kong Special Administrative Region, China (EdUHK 18603618).

\section{References}

Alharbi, M. A., \& Al-Hoorie, A. H. (2020). Turnitin peer feedback: Controversial vs. non-controversial essays. International Journal of Educational Technology in Higher Education, 17, 1-17.

Butler, D. L., \& Winne, P. H. (1995). Feedback and self-regulated learning: A theoretical synthesis. Review of Educational Research, 65(3), 245-281.

Campbell, J., \& Li, M. (2007). Asian students' voices: An empirical study of Asian students' learning experiences at a New Zealand University. Journal of Studies in International Education, 12(4), 375-396.

Carless, D., \& Boud, D. (2018). The development of student feedback literacy: Enabling uptake of feedback. Assessment \& Evaluation in Higher Education, 43(8), 1315-1325.

Charmaz, K. (2014). Constructing grounded theory. Sage.

Cheng, D., \& Li, M. (2020). Screencast video feedback in online TESOL classes. Computers and Composition, 58, 102612.

Farrell, T. S. C. (2012). Novice-service language teacher development: Bridging the gap between preservice and in-service education and development. TESOL Quarterly, 46(3), 435-449.

Fletcher, A. K. (2017). Helping seeking: Agentic learners initiating feedback. Educational Review, 70(4), 389-408.

Hattie, J., \& Timperley, H. (2007). The power of feedback. Review of Educational Research, 77(1), 81-112.

Hsu, S. (2005). Help-seeking behavior of student teachers. Educational Research, 47(3), 307-318.

Hwang, G., Wang, S., \& Lai, C. (2021). Effects of a social regulationbased online learning framework on students' learning achievements and behaviors in mathematics. Computers \& Education, $160,104031$.

Johnson, K. E. (2009). Second language teacher education: A sociocultural perspective. Routledge.

Karabenick, S. A. (2006). Introduction. In S. A. Karabenick \& R. S. Newman (Eds.), Help seeking in academic settings: Goals, groups, and contexts (pp. 1-13). Lawrence Erlbaum Associates.

Karabenick, S. A., \& Knapp, J. R. (1991). Relationship of academic help seeking to the use of learning strategies and other instrumental achievement behavior in college students. Journal of Educational Psychology, 83(2), 221-230.

Liu, F., Du, J., Zhou, D. Q., \& Huang, B. (2021). Exploiting the potential of peer feedback: The combined use of face-to-face feedback and e-feedback in doctoral writing groups. Assessing Writing, 47(4), 100482.

Merriam, S. (1998). Qualitative research and case study applications in education. Jossey-Bass.

Mory, E. H. (2004). Feedback research revisited. In D. H. Jonassen (Ed.), Handbook of research on educational communications and technology (pp. 745-783). Lawrence Erlbaum Associates Publishers.
Nelson-Le Gall, S. (1981). Help-seeking: An understudied problem solving skill in children. Developmental Review, 1, 224-246.

Newman, R. (2002). How self-regulated learners cope with academic difficulty: The role of adaptive help seeking. Theory into Practice, 41(2), 132-138.

Newman, R. S. (2008). The motivational role of adaptive help seeking in self-regulated learning. In D. H. Schunk \& B. J. Zimmerman (Eds.), Motivation and self-regulated learning: Theory, research, and applications (pp. 315-337). Lawrence Erlbaum Associates Publishers.

Nicol, D. (2020). The power of internal feedback: Exploiting natural comparison process. Assessment \& Evaluation in Higher Education. https://doi.org/10.1080/02602938.2020.1823314

Pintrich, P. R. (2004). A conceptual framework for assessing motivation and self-regulated learning in college students. Educational Psychology Review, 16(4), 385-407.

Ryan, A. M., \& Pintrich, P. R. (1997). "Should I ask for help?" The role of motivation and attitudes in adolescents' help seeking in math class. Journal of Educational Psychology, 89(2), 329-341.

Sato, K., \& Mutoh, N. (2019). Longitudinal research on EFL teacher professional development in (Japanese) contexts: Collaborative action research projects. Language Teaching Research. https://doi.org/10.1177/1362168819893814

Strauss, A., \& Corbin, J. (1998). Basics of qualitative research: Techniques and procedures for developing grounded theory (2nd ed.). Sage.

Ware, P. D., \& Warschauer, M. (2006). Electronic feedback and second language writing. In K. Hyland \& F. Hyland (Eds.), Feedback in second language writing: Context and issues. Cambridge University Press.

Weber, K. E., Gold, B., Prilop, C. N., \& Kleinknecht, M. (2018) Promoting pre-service teachers' professional vision of classroom management during practical school training: Effects of a structured online- and video-based self-reflection and feedback intervention. Teaching and Teacher Education, 76, 39-49.

$\mathrm{Yu}, \mathrm{S}$. (2019). Learning from giving peer feedback on postgraduate theses: Voices from Master's students in the Macau EFL context. Assessing Writing, 40, 42-52.

Yuan, Y. (2003). The use of chat rooms in an ESL setting. Computers and Composition, 20, 194-206.

Yuan, R., \& Lee, I. (2014). Pre-service teachers' changing beliefs in the teaching practicum: Three cases in an EFL context. System, $44,1-12$.

Yuan, R., Mak, P., \& Yang, M. (2020). 'We teach, we record, we edit, and we reflect': Engaging pre-service language teachers in video-based reflective practice. Language Teaching Research. https://doi.org/10.1177/1362168820906281.

Zimmerman, B. J. (2005). Attaining self-regulation: A sociocognitive perspective. In M. Boekaerts, P. R. Pintrich, \& M. Zeidner (Eds.), Handbook of self-regulation (pp. 13-39). Elsevier Inc.

Publisher's Note Springer Nature remains neutral with regard to jurisdictional claims in published maps and institutional affiliations. 